\title{
La coeducación patrimonial o cómo aplicar la perspectiva de género en la educación patrimonial en instituciones culturales y museos
}

\author{
Heritage coeducational approach, or how to apply \\ a gender perspective in heritage education \\ in cultural institutions and museums
}

\section{Maria Cacheda*}

\footnotetext{
* Agència Catalana del Patrimoni Cultural, Generalitat de Catalunya, Departament de Cultura. Licenciada en Historia del Arte con estudios de doctorado y DEA en Arqueología, Historia de la Antigüedad y Ciencias y Técnicas Historiográficas. Coordinadora de la Acción Educativa del Área de Monumentos y Yacimientos de la Agència Catalana del Patrimoni Cultural de la Generalitat de Catalunya. Investigadora del grupo Centro de Estudios del Patrimonio Arqueológico de la Prehistoria (CEPAP) de la Universidad Autónoma de Barcelona.

$\varangle \cdot$ mcacheda@gencat.cat https://orcid.org/0000-00033614-0104
}

RECIBIDO: 26.7 .2019

ACEPTADO: 29.9.2019

\section{Resumen}

La coeducación es una metodología pedagógica utilizada en la educación formal, que va más allá de la educación mixta y es la base para educar en igualdad a niños, niñas y adolescentes sin discriminación por razones de género. Pretende la desaparición de cualquier tipo de exclusión o infravaloración, la superación de estereotipos sexistas y la eliminación de roles y jerarquías de género androcéntricos en el desarrollo educativo desde los primeros años de escolarización de niños y niñas. La coeducación aplica la perspectiva de género a las prácticas educativas, que cuando se da en un contexto patrimonial se transforma en coeducación patrimonial. El objetivo del artículo es acercar al lector al conocimiento de una nueva metodología educativa basada en la coeducación patrimonial, a fin de poder aplicarla en los programas educativos ofrecidos a los centros educativos por museos e instituciones patrimoniales, para garantizar una educación igualitaria y no discriminatoria, que ayude a formar personas críticas, justas y libres.

Palabras clave: metodología, educación, patrimonio cultural, arqueología, museo. 


\begin{abstract}
The coeducational approach as a pedagogy in formal education, goes beyond no singlesex education and is the basis for educating children and adolescents equally, without gender discrimination. It seeks to suppress all forms of exclusion or undervaluation, to overcome sexist stereotypes and to eliminate androcentric gender roles and hierarchies from the first years of schooling for boys and girls and along their educational development. The coeducational approach mainstreams a gender perspective through practical tools; when applied in a heritage context it becomes a heritage coeducational approach. The objective of the article is to bring the reader closer to the knowledge of a new educational methodology based on the heritage coeducational approach, to be able to apply it in the educational programs offered to schools by museums and heritage institutions, to guarantee an equal and non-discriminatory education, thus helping to form critical, fair-minded and free people.
\end{abstract}

Keywords: methodology, education, cultural heritage, archaeology, museums.

\title{
Introducción 1
}

La metodología educativa que se presenta en este artículo plantea la necesidad de una investigación y revisión profunda de la educación patrimonial que se desarrolla en el ámbito de museos e instituciones patrimoniales, a fin de integrar una visión coeducativa. Con esta mirada que integra la perspectiva de género, la educación patrimonial que se lleva a cabo en el museo busca reconocer las potencialidades e individualidades de todo el alumnado que participa en el desarrollo de las actividades educativas, potenciar la igualdad real de oportunidades, sin tener en cuenta el género en lo que se refiere al acceso a la participación y a las capacidades como trato equivalente o justo, considerando previamente las diferencias y desigualdades (García Prince, 2008).

La educación patrimonial más tradicional perpetúa los roles arraigados en la educación formal basada en la transmisión de conocimientos de manera unidireccional, donde la persona educadora, desde una posición de preeminencia, vehicula unos conocimientos curriculares y patrimoniales basados en un sistema educativo obsoleto y androcéntrico, sin tener en cuenta las necesidades de las personas que participan, con lo

1 Este artículo se enmarca en la investigación de la autora para la tesis doctoral que realiza en la Universidad Autónoma de Barcelona, sobre nuevas metodologías educativas basadas en la coeducación patrimonial para aplicarlas a museos y centros de interpretación sobre la Prehistoria. A la vez, la metodología que aquí se expone, creada por la autora, fue probada en el Museo de Arte Precolombino e Indígena de Montevideo durante el mes de octubre de 2019, gracias a una beca de capacitación de Ibermuseos, principal programa de cooperación para los museos existentes en la región. 
que impide su proceso evolutivo y de desarrollo (Subirats y Tomé, 2007 y Cacheda Pérez, López Basanta y Torres Fernández (2017).

El objetivo principal del trabajo en coeducación patrimonial del Área de Monumentos y Yacimientos de la Agencia Catalana del Patrimonio Cultural (ACdPC, a partir de ahora), y el objetivo de esta propuesta, es afrontar el reto de establecer nuevas estrategias metodológicas en educación patrimonial, basadas en la coeducación y la introducción de la perspectiva de género; de-construir la educación patrimonial tradicional e introducir metodologías activas y coeducativas con el alumnado, que incidan en una educación igualitaria, justa y democrática, para transformarla en coeducación patrimonial.

La metodología se ha puesto en funcionamiento en el Conjunto Rupestre de la Roca de los Moros del Cogul (Les Garrigues, Lleida, Cataluña), un yacimiento arqueológico con pinturas rupestres datadas desde el epipaleolítico hasta la romanización del territorio catalán. La prehistoria, temática de las actividades educativas del Centro de Interpretación, es un buen ejemplo de período histórico en que el papel de la mujer y otras diversidades de la sociedad del pasado han estado invisibilizados dentro de las narrativas del currículo educativo, patrimonial y científico, y a través de esta propuesta se quieren hacer visibles.

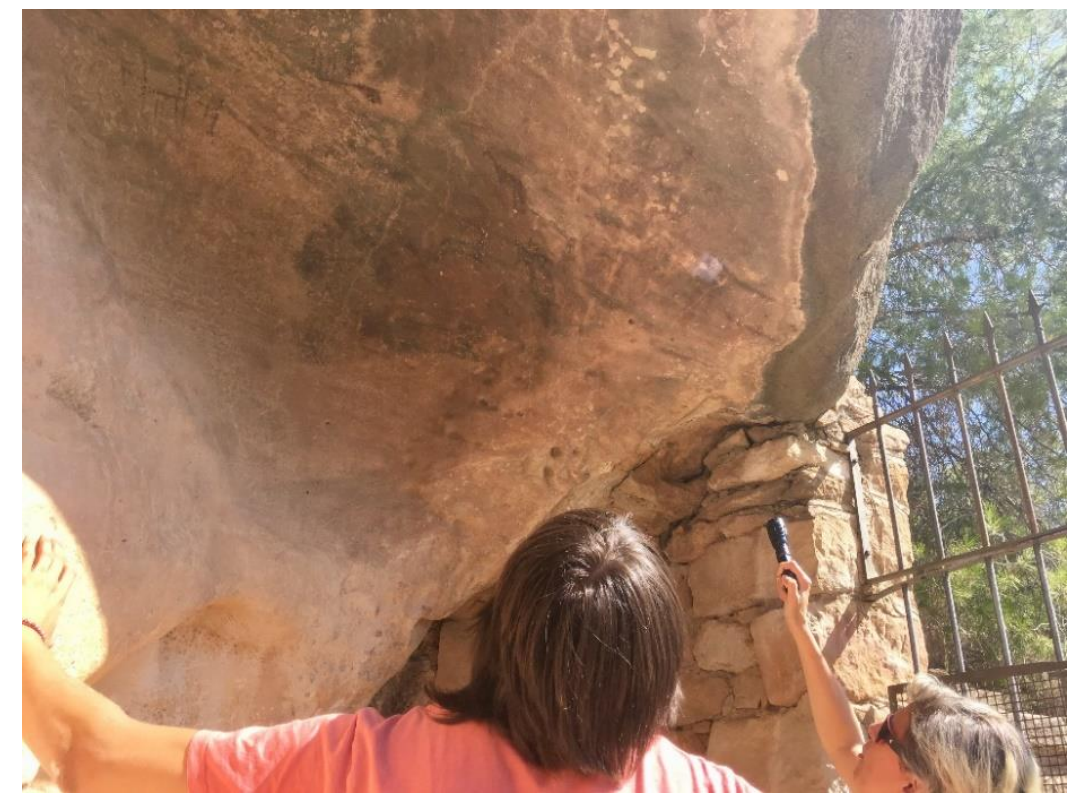

Figura 1. Detalle de la Roca de los Moros del Cogul. Fotografía: Cacheda (2018). 
La introducción de la perspectiva coeducadora a través de la práctica en el museo se lleva a cabo en los programas de actividades educativas de diferentes monumentos históricos y yacimientos arqueológicos musealizados, en el Área de Monumentos y Yacimientos de la ACdPC. A través de una metodología propia y cualitativa de análisis, durante el desarrollo de la actividad educativa se tratan los siguientes parámetros: el lenguaje utilizado (ámbito de la comunicación, cómo nos comunicamos), el ámbito organizativo y las relaciones creadas con el alumnado (ámbito de la convivencia y ocupación de los espacios del museo), el discurso que transmite el museo y los materiales pedagógicos utilizados (narrativas, ilustraciones...) y cómo se enseña (metodología y práctica educativa), para reflexionar y modificar la distorsión androcéntrica integrada en la sociedad actual.

\section{Educación patrimonial y perspectiva de género}

En los últimos años, la educación patrimonial en España ha sido foco de investigación creciente en diferentes puntos del país. Bajo este prisma, en el 2010 se conforma el Observatorio de Educación Patrimonial en España (http://www.oepe.es/) y se localizan, inventarían, analizan y evalúan programas del ámbito nacional e internacional que trabajan desde la educación patrimonial. La educación en museos e instituciones patrimoniales es considerada el motor del museo, organizaciones educativas de primer orden donde niños, niñas y adolescentes también aprenden a socializarse a través de las actividades y propuestas educativas que se les ofrecen.

Estos nuevos programas de actividades se suman a la revolución educativa que se está llevando a cabo en España y que en Cataluña, en esta última década, se ha impulsado a través del Departamento de Educación (http://ensenyament.gencat.cat/ca/inici). Se apuesta por una nueva manera de enseñar que pasa por un trabajo competencial y significativo, en el que el alumnado es el protagonista de su propio proceso de aprendizaje.

En el ámbito patrimonial, en Cataluña también se ha creado en 2014 la Agencia Catalana del Patrimonio Cultural (Generalitat de Catalunya, 2016) dentro del Departamento de Cultura de la Generalitat de Catalunya, que desde el 2015 aboga por una acción educativa transformadora en sus monumentos históricos y yacimientos arqueológicos, teniendo en cuenta los parámetros de innovación en los que se trabaja en los centros educativos del país. Se busca un cambio de las didácticas, las metodologías, los horarios, el uso de los espacios y la arquitectura, una nueva manera de organizar el relato del museo, de evaluarlo y de relacionarlo con el alumnado y con la comunidad. Estos cam- 
bios conceptuales quieren apostar por trabajar el talento propio de niños, niñas y adolescentes y potenciar sus capacidades, un reto que la educación patrimonial tiene que asimilar para que el museo sea un recurso educativo de calidad, relevante e inclusivo.

Todo esto encamina a redefinir las funciones sociales y educativas del museo, a trabajar las competencias cognitivas como la iniciativa, el trabajo en equipo, la colaboración, la creatividad; en definitiva, las habilidades sociales adaptadas al alumnado de la escuela del siglo XXI: iniciativa, empatía, trabajo en grupo, persistencia, colaboración, creatividad. Las instituciones patrimoniales y los museos tienen la obligación de participar activamente en la construcción de un cambio social equitativo, ya que son un lugar privilegiado para facilitar esta transformación.

La educación patrimonial es una pieza esencial para reducir las desigualdades, y reflexionar sobre ello. Por eso la coeducación y la aplicación de la perspectiva de género, la coeducación patrimonial, es una alternativa más para parar la reproducción de las desigualdades y construir ciudadanías más justas y libres (Cacheda Pérez, López Basanta y Torres Fernández, 2017).

El objetivo de la coeducación (patrimonial, en este caso) es transmitir una socialización de los géneros que elimine los aspectos negativos y las jerarquías de los modelos vigentes, y abra camino al pleno desarrollo de cada criatura en todas las dimensiones de la vida y en las capacidades que necesitará tener para enfrentarse a la sociedad, con base en la confianza y el acompañamiento de educadoras y educadores (Roset Fàbrega, 2008).

\section{Caso de estudio: Conjunto Rupestre de la Roca de los Moros del Cogul}

El Conjunto Rupestre de la Roca de los Moros del Cogul es uno de los espacios más emblemáticos del arte levantino del Arco Mediterráneo de la Península Ibérica y fue declarado patrimonio de la humanidad por la UNESCO en 1998. Está situado en el pequeño municipio del Cogul (Lleida) y se trata de una cavidad que fue empleada por diferentes sociedades durante más de 10.000 años como lugar de culto. Sus composiciones, grabados y pinturas fueron de los primeros en divulgarse por su factura y calidad.

La riqueza interpretativa lo hace un lugar muy atractivo para abordar temas de género e igualdad social. El mural se convierte en un potente recurso educativo donde la reflexión sobre la escena principal, un grupo de mujeres que parece que bailan cerca de un hombre más pequeño, desnudo y con un miembro desproporcionado, dio lugar a diferentes teorías sobre una danza fálica por la comunidad científica que las descubrió y estudió (Breuil, 1908 y Cabré Aguiló, 1915), en la que el hombre era el protagonista 
de un ritual de fertilidad. Hoy en día, por los estudios realizados (Viñas, Rubio, Iannicelli y Fernández Marchena, 2017), sabemos que el dibujo de las mujeres es el resultado de un proceso de figuras acumulativas, de parejas pintadas en diferentes momentos históricos alrededor de la figura masculina, que probablemente fue pintada en último lugar en la escena (Escoriza Mateu, 2005), con lo que el discurso original no se sostiene y la lectura centrada en el hombre se desmonta. El Cogul es un lugar ideal para romper los estereotipos y roles de género androcéntricos que asume la sociedad actual como relaciones sociales consolidadas.

En 2015, la Agencia Catalana del Patrimonio Cultural pone en marcha el programa educativo patrimonial, investigando, estudiando y aplicando la coeducación patrimonial. Se trata de superar el modelo de enseñanza transmisor más tradicional (Acaso y Manzanera, 2015) para posibilitar que los niños, las niñas y las personas jóvenes puedan disfrutar en los espacios patrimoniales de experiencias de aprendizaje relevantes y con sentido para mejorar su expectativa vital en dignidad, capacidad y bienestar. Las actividades están diseñadas para permitir que las criaturas lleguen a ser personas autónomas con una vida plena y, como consecuencia, que ello revierta también en una sociedad más cohesionada y capaz de dar respuesta a los retos globales, formando ciudadanos y ciudadanas libres y responsables.

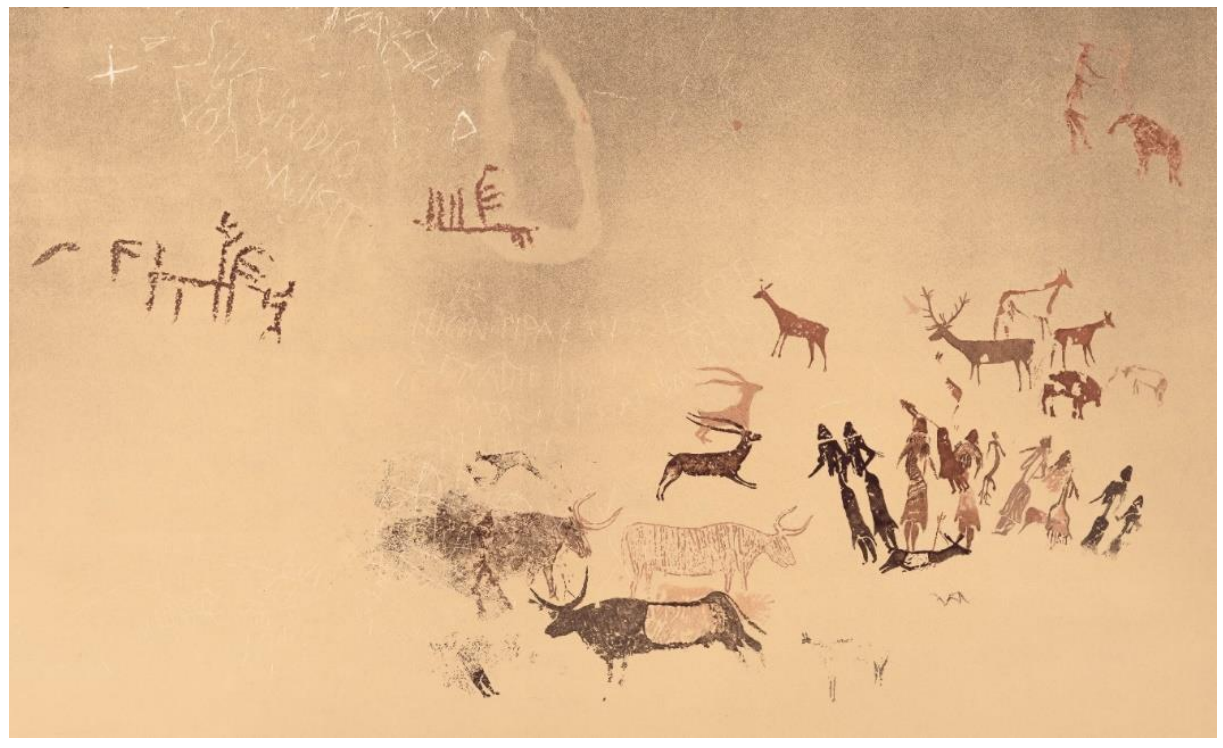

Figura 2. Calco de las pinturas. Imagen: R. Viñas, A. Alonso y E. Sarriá (2008). Exposición: Un espacio sagrado. 
El programa educativo del Conjunto Rupestre de la Roca de los Moros está formado por una serie de actividades de tipo mediación-taller, sin un tiempo de realización limitado, pensadas para diferentes niveles educativos. Siguen los principios competenciales de cada área de conocimiento y priorizan el trabajo cooperativo, la iniciativa y la autonomía del alumnado, además de la reflexión continuada. Con una metodología donde la persona educadora hace de facilitadora entre las pinturas, el patrimonio y el alumnado, se consigue crear reflexiones y debate en que chicas y chicos generan más preguntas que respuestas, interviniendo en el discurso del relato, conectando el pasado con su presente y sintiéndose sujetos activos del aprendizaje de una manera crítica, constructiva y significativa.

\section{Ámbitos de acción de la coeducación patrimonial}

Se propone una metodología coeducativa que pone el foco de atención en tres ámbitos a la hora de detectar y transmitir una socialización de los géneros que elimine los aspectos negativos y las jerarquías de los modelos vigentes, y abra así el camino al pleno desarrollo de cada niño o niña en todas las dimensiones de la vida y capacidades que necesitará tener en la sociedad actual y futura (Subirats, 2017).

Los ámbitos de transformación para aplicar la coeducación patrimonial son los siguientes:

- Los saberes de referencia: cambio de las narrativas, el relato, discursos y materiales educativos (la interpretación de las pinturas, en este caso, y de la prehistoria).

- El lenguaje: tomar conciencia de la discriminación lingüística en el discurso propio y escrito, en los materiales y recursos: lo que no se nombra no existe y las niñas no se ven representadas en lo que les transmitimos, porque no están presentes. El masculino universal no es neutro, no incluye otros géneros.

- El ámbito relacional: la ocupación del espacio y la relación entre la persona educadora y el alumnado, y entre niños y niñas. Trabajar estrategias de la comunicación no violenta en la manera de relacionarnos: escucha activa, asertividad, diálogo, parafraseo, trabajo en equipo, respeto, empatía, creatividad, etcétera. En definitiva, trabajar una cultura de paz a través de las competencias emocionales y estrategias didácticas que incluyan por igual a niñas y a niños. 


\section{Los saberes de referencia: relato de la prehistoria}

Dentro de este campo hay mucho recorrido hecho. La arqueología feminista en España se ha dedicado desde los años ochenta del siglo XX a denunciar la ausencia de visibilidad de las mujeres y otras diversidades — como, por ejemplo, niños, niñas, gente mayor o enferma- dentro de las narrativas, los discursos, las ilustraciones y las imágenes que se encuentran en las salas de los museos y nos explican la sociedad prehistórica. En la arqueología feminista existen numerosas referentes que se han ocupado del lenguaje icónico, de denunciar el uso de las imágenes sexistas y de los estereotipos de género aplicados a las escenas y los relatos que explican la prehistoria en estos espacios educativos y de construcción de conocimiento como son los museos y centros de interpretación patrimoniales.

\section{La relevancia educativa de la prehistoria}

La mayoría de los estudios antropológicos y culturales que hacen alusión a la identidad de grupos prehistóricos poco complejos socioeconómicamente coinciden en destacar la importante base relacional, colectiva o interdependiente de todas las personas del grupo social (Hernando, 2005).

A medida que las sociedades se fueron haciendo más complejas con la división de funciones y la especialización del trabajo, determinados hombres del grupo social empezaron a ocupar posiciones diferentes del resto, para entender las dinámicas de la naturaleza a través de fórmulas abstractas y, por consiguiente, desacralizar algunos de sus fenómenos. El desarrollo tecnológico que progresivamente se instalaba iba definiendo la individualidad de estas personas, que pasaban a ocupar posiciones especializadas y empezaban a encontrar seguridad en su propia capacidad de entender y controlar el mundo, por lo que su vinculación con el grupo dejaba de constituir el mecanismo de reafirmación y reforzamiento personal. Dejaban de participar en las actividades productivas recurrentes y no especializadas, las no asociadas al poder ni al mantenimiento del grupo, que fueron quedando en manos de las mujeres como una manera de garantizar la existencia y la supervivencia del colectivo.

Estas personas que se individualizaban en las sociedades prehistóricas eran en su mayoría hombres. Se sabe porque las primeras tumbas masculinas individualizadas, datadas antes del megalitismo o a la edad del bronce, contenía ajuares funerarios de lujo y prestigio que los diferencian del grupo (Hernando, 2007).

También se observa que la historia no ha contemplado la función de las mujeres. Desde hace unos veinte años, muchas arqueólogas han estudiado y reflexionado para evidenciar el papel de la mujer en la prehistoria, como Paloma González Marcén (2000, 
2006, 2008, 2012), profesora titular de la Universidad Autónoma de Barcelona, o Margarita Sánchez Romero (2005, 2007, 2008, 2010, Sánchez Romero y Alarcón García, 2015), profesora titular de la Universidad de Granada, o la antropóloga Almudena Hernando (2002, 2012, 2015), ya mencionada, de la Universidad Complutense de Madrid. Sus reflexiones sobre la importancia del papel de la mujer en el pasado, la arqueología feminista y los mecanismos a través de los cuales se ha construido la propia invisibilización de la mujer en la historia y la arqueología, son de vital importancia para repensar el relato del pasado.

Según estas investigadoras, «las actividades de mantenimiento» (González Marcén y Picazo Gurina, 2005) — que se asocian a las actividades de cura, procesado de los alimentos y reproducción del grupo, entre otras - son actividades no especializadas, no asociadas al cambio sino a la recurrencia, que se ejecutan en espacios conocidos y se asocian al sostenimiento de los vínculos y la cohesión afectivo-relacional del colectivo al que se pertenece. Son impersonales, anónimas y caracterizan la manera de hacer del grupo. Han garantizado la viabilidad de la comunidad, la posibilidad de que la complejidad socioeconómica aumentara sin que el clan se desmembrara a medida que lo hacía. Han permitido que las individualidades masculinas se fueran construyendo, sin que ello implicara la pérdida de sentido en el mundo para aquellas personas que iban ejerciendo aquel control del mundo.

Estas actividades de mantenimiento no se han transmitido en la arqueología tradicional, lo que invisibiliza el papel de la mujer en las sociedades del pasado y da protagonismo a las acciones de producción y tecnológicas, llevadas a cabo por los hombres.

Tales diferencias han generado una transmisión androcéntrica de la narración de la prehistoria, centrada en el hombre y en todo el ámbito considerado masculino. Las tareas masculinas se han considerado las importantes dentro de las sociedades prehistóricas, mientras que las femeninas, igual de importantes para la supervivencia de los grupos sociales, se han obviado.

Las actividades de mantenimiento, aparte de las diversas formas de trabajo que representan, han recibido poco interés de la investigación arqueológica. Esta ausencia resulta paradójica, ya que la evidencia empírica de este tipo de actividades constituye una parte muy importante del registro arqueológico en cualquier cultura y período histórico. Los materiales recuperados en contextos arqueológicos se relacionan con los trabajos de mantenimiento y cuidados. Estas actividades formaban parte indisoluble de la complejidad y la supervivencia de las sociedades del pasado y no se les ha dado la importancia que tienen, debido, sin duda, a que son actividades realizadas por mujeres (González Marcén y Picazo Gurina, 2005).

Las estudiantes no encuentran referentes propios en esta manera de explicar la historia, porque los currículos de las asignaturas y los libros de texto no valoran por igual las aportaciones de las mujeres y de los hombres. Ellas no están representadas, no 
se encuentran, admiten desde niñas que no son importantes, con lo que incorporan a su subconsciente e imaginario individual y colectivo la invisibilización a la que una sociedad androcéntrica las somete (Arranz, 2015). Tampoco se encuentran en las salas de los museos, ni en su discurso, ni en las fotografías, ni en las vitrinas, donde se perpetúan el rol masculino y la importancia del hombre a lo largo de la historia.

En el programa educativo del Conjunto Rupestre del Cogul, para ayudar a la comprensión sobre las sociedades pasadas a los y las más pequeñas, se ha diseñado un conjunto de ilustraciones que acompañan un discurso inclusivo. Las ilustraciones, siguiendo unos indicadores específicos para valorar y visibilizar las tareas femeninas y la diversidad social, fueron realizadas por la ilustradora Helena Rovira en 2017.

A nivel metodológico se habían construido previamente una serie de indicadores cualitativos para garantizar un discurso inclusivo socialmente. En el momento de representar escenas sobre la prehistoria se ha tenido en cuenta:

- El rigor histórico tiene que aplicarse por presencia y por ausencia; no añadir elementos a la escena para completarla si no se está seguro, a través de las fuentes y la investigación, de si había ciertos objetos o no.

- Si no hay la evidencia científica en cuanto al género, representar la diversidad de manera igualitaria.

- Evitar estereotipos de género, huir de los cuerpos heteronormativos e introducir la diversidad física. Que sean cuerpos reales, no idealizados, y que sean visibles las patologías de las que sí tenemos evidencias científicas en algunos casos.

- Que las escenas sean reales, creíbles. Contemplar la diversidad emocional, las expresiones y las actitudes de las personas. Eliminar imágenes melancólicas o mujeres y criaturas en actitudes pasivas.

- No representar familias nucleares, idea arraigada en la sociedad actual pero que no sabemos cómo era en el pasado, y representar la diversidad de vínculos entre las personas.

- Conectar la tecnología y la cultura material en general también con las mujeres, ya que no hay evidencias de que no participasen; por ejemplo, las tareas de producción como la metalurgia y la elaboración de herramientas de piedra. Los trabajos activos de supervivencia de la especie, como la caza, la recolección, la ganadería o la agricultura, también se tienen que conectar con el universo femenino y la diversidad, puesto que no sabemos que fuera diferente.

- Visibilizar la colaboración y la interacción entre los miembros del grupo para evidenciar que todo el mundo participaba, no solo el hombre, como se ha presentado tradicionalmente. Buscar que prevalezca la acción colectiva y no la individual para favorecer la equidad y que todas las personas participen en esa acción en igualdad de condiciones. 
El resultado es visible en las ilustraciones, pensadas y creadas sobre estas premisas:

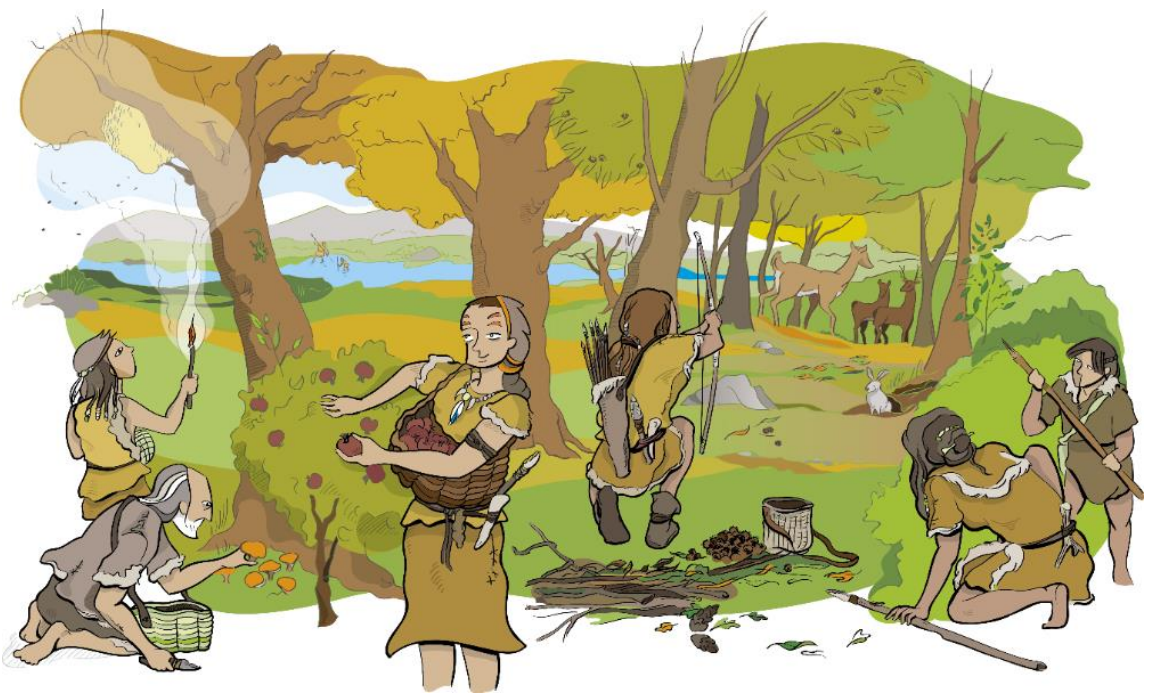

Figura 3. Foto ilustración sobre la caza y la recolección. Imagen: Helena Rovira (2017).

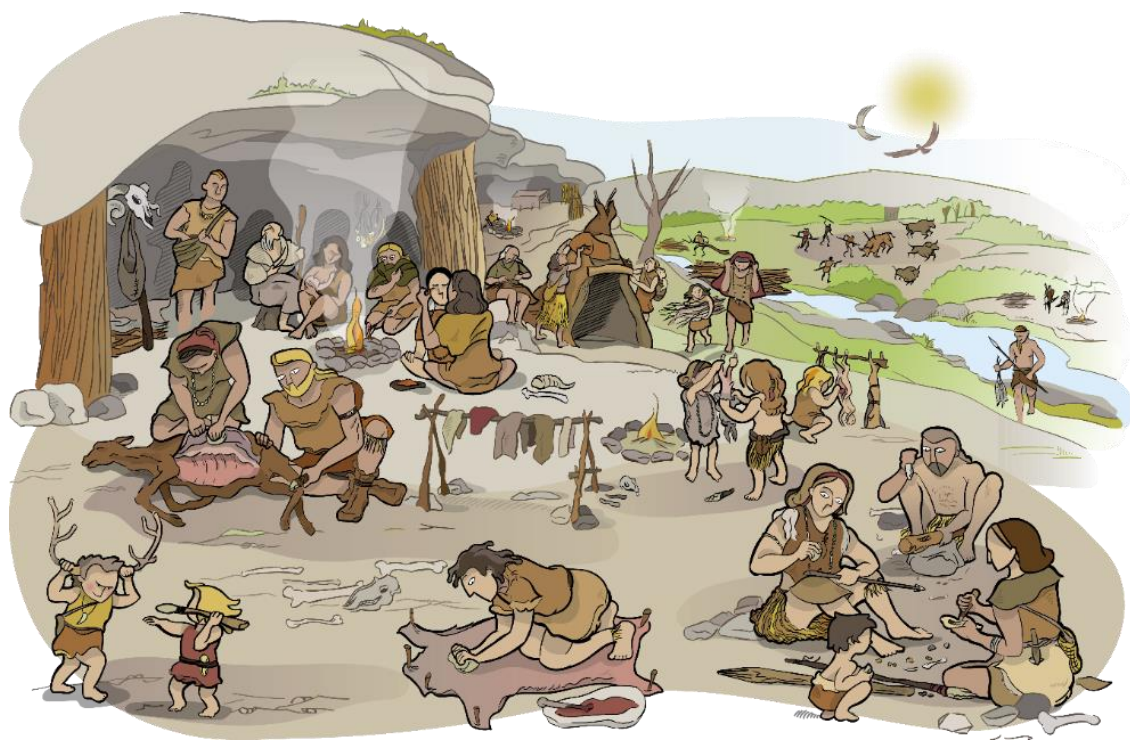

Figura 4. Foto ilustración sobre la sociedad del Epipaleolítico. Imagen: Helena Rovira (2017). 
Una educación igualitaria tiene que valorar por igual las aportaciones de mujeres y hombres, y transmitirlas a todas las personas de las nuevas generaciones, sean hombres o mujeres, para que las criaturas se desarrollen con libertad y puedan desplegar todas sus potencialidades y facultades a lo largo de su vida. Este es el reto de la coeducación patrimonial, un cambio cultural profundo para avanzar en la igualdad y la equidad, que se trabaja por primera vez en educación patrimonial, teniendo en cuenta, además del relato, el lenguaje que se utiliza y el aspecto relacional, aspectos primordiales en la coeducación formal y que no se habían trabajado antes en educación patrimonial (Cacheda, 2018).

\section{El lenguaje: la discriminación lingüística}

La manera como utilizamos el lenguaje oral y escrito tiene que ver con la manera como definimos la realidad en el intercambio comunicativo, por lo que afecta la forma en que accedemos al conocimiento del mundo y de nuestra realidad.

Cuando escribimos un texto, revisamos muchas veces que sea correcto lingüística y gramaticalmente, pero no nos preocupamos por que sea inclusivo, que tenga en cuenta la diferencia de género en el corpus de lo escrito. Cuando hablamos, pasa lo mismo: usamos fórmulas genéricas, dando por hecho que el masculino genérico incluye a todos los géneros. Cambiar este sistema tan arraigado de dominio en nuestro imaginario, que el masculino genérico incluye a todos los géneros, supone un trabajo de concienciación y cuestionamiento, para después pasar a la experimentación con otros tipos de discurso y buscar nuevas maneras de comunicarnos. Reconocer a niñas y niños de todas las edades pasa por incluir de manera cotidiana ambos sexos en el lenguaje que usamos.

La función del lenguaje es la comunicación, mediante la cual transmitimos valores, actitudes, ideas y prejuicios que refuerzan estereotipos sexistas existentes en nuestra sociedad. Proyectamos una realidad y le damos forma haciendo un uso sexista y androcéntrico de la lengua porque vivimos en una cultura que así lo integra, en la que se valoran las capacidades y funciones atribuidas a los hombres y no se reconocen los valores de las capacidades y funciones atribuidas a las mujeres (Roset, 2008).

El sexismo, dice Eulàlia Lledó (2005, p. 49), doctora en filología y especialista en coeducación, «es una actitud caracterizada por el desprecio y la desvalorización, por exceso o por defecto, de lo que son o hacen las mujeres. El sexismo es una actitud derivada de la supremacía masculina y se basa en la hegemonía de los hombres y en todas aquellas creencias que la soportan y la legitiman». A través de los estereotipos sexistas se fija un único modelo de ser hombre y un único modelo de ser mujer, válidos socialmente, y a partir de esta imagen tópica construida se establece un sistema desigual de 
relaciones entre los dos sexos y la invisibilización de los géneros no normativos, que se refleja también en el lenguaje.

Si nos fijamos en el uso cotidiano de nuestro lenguaje podremos identificar rasgos sexistas como, por ejemplo, el uso abusivo del género masculino para designar todos los individuos, mujeres y hombres, que constituimos la humanidad, o a un colectivo diverso (el habitual hombre: hombre de cromañón, el hombre prehistórico, etcétera). Esto tiene como consecuencia una desvalorización del género femenino y su invisibilidad, donde las mujeres se tienen que adaptar a su presencia o ausencia. En cuanto a la gramática sobre esta norma, cuando nos referimos a dos nombres o más, cuando hay femeninos y masculinos, usamos el masculino plural, transmitiendo a niñas y niños un mensaje discriminatorio y sexista: que el masculino predomina por encima del femenino. Se continúa así construyendo una realidad sexista, sobre todo a través de la reiteración del masculino genérico, socialmente aceptado, que responde a una discriminación por la que las niñas no se sienten representadas y acaban integrando que ellas no son importantes, ya que no se las nombra (Subirats, 2017).

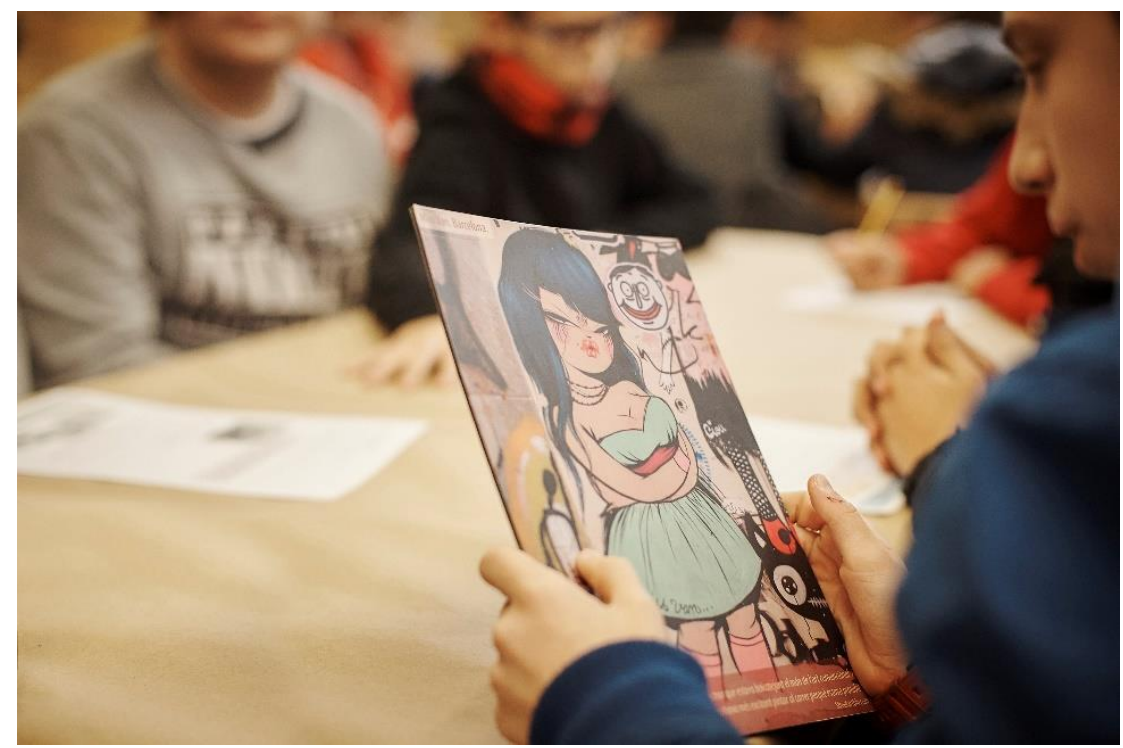

Figura 5. Trabajando los estereotipos en las actividades educativas del Centro de Interpretación del Cogul. Fotografía: Paco Amate (2016). 
Y esto tiene consecuencias graves desde que son pequeñas. Como las personas educadoras no se dirigen a ellas, las niñas no se sienten autorizadas a hablar, a intervenir durante las prácticas educativas. Los estudios hechos sobre este tema por Marina Subirats y C. Brullet, publicados en el libro Rosa y Azul, la transmisión de los géneros en la escuela mixta (1988), demuestran que las niñas hablan menos en las clases que los niños, intervienen mucho menos y, cuando lo hacen, se refieren más a menudo a cuestiones relativas a lo que se está tratando en ese momento en el aula que a temas personales o familiares, que sí introducen los niños durante las prácticas educativas. También con estos estudios se ha demostrado que las personas educadoras se dirigen más a los niños, hablan más con ellos, hecho que se midió a través del número de palabras que dirigían a unos y otras. En el entorno latinoamericano también son importantes los estudios realizados por Sandra Araya sobre las relaciones sexistas que se establecen en el entorno educativo, que nos aportan resultados similares (Araya Umaña, 2003).

Marina Subirats concluyó que los y las docentes están más centradas en los niños; el sujeto de la educación es el niño. La niña tiene que estar atenta a las otras personas, ver cómo las puede ayudar, pero no es la protagonista del hecho educativo. En esta manera de relacionarse alumnado y profesorado entrarían los estereotipos de género normalizados en los imaginarios de las personas educadoras, por los tipos de relaciones que establecen con los niños y con las niñas (Subirats, 2017). Se transmite sexismo también con las insinuaciones, atribuyendo a un género roles no convencionales como si estos fueran propios de uno solo, no de los dos. Hay muchos ejemplos en el entorno educativo — «las niñas son más inteligentes», «los niños son más movidos», etcétera一, y esto se refleja en las relaciones y también en el tiempo que se dedica a los niños o a las niñas cuando el profesorado se dirige a ellos o ellas. El cómo y el cuánto, que cada criatura va integrando, tiene que ver con la socialización de las educadoras, y como consecuencia, incidirá en las relaciones que niños y niñas van asimilando. Las lenguas son vivas y cambiantes, y esto explica que, si pedimos un trato equitativo entre mujeres y hombres, el lenguaje que utilicemos, como producto social construido, tiene que reflejar esta igualdad y tiene que contribuir a lograrla. Para Montserrat Roset Fàbrega (2008, p. 31):

[...] actuar sobre la lengua, proponiendo alternativas para evitar la discriminación femenina, puede contribuir positivamente a sensibilizar las personas que formen parte de la comunidad educativa y ayudar a conseguir unos hábitos sociales más respetuosos y equitativos respecto de las niñas, chicas y mujeres que conviven. En este sentido la modificación de hábitos lingüísticos cotidianos arraigados se revela mucho más eficaz que las solemnes declaraciones de principios. 
Es preciso tener presente que los hábitos lingüísticos de las personas educadoras actúan como modelo que sigue el alumnado, tanto en el aula como en las instituciones patrimoniales y los museos, en todos los procesos de enseñanza-aprendizaje, por lo que asumir fórmulas inclusivas en el lenguaje contribuye a desterrar la permanencia de usos tradicionales sexistas. Se trata de un objetivo que exige concienciación y esfuerzo: primero la revisión del lenguaje sexista y después la sustitución por fórmulas inclusivas que reconozcan en el mismo grado de protagonismo a niñas y niños. No hacerlo legitima la invisibilidad y la discriminación de las mujeres en el uso de la lengua.

Existen alternativas para hacerlo y muchos manuales publicados por diversas instituciones para el uso no sexista de la lengua y sobre cómo podemos integrar un lenguaje inclusivo a la hora de comunicarnos hablando o escribiendo. Algunos ejemplos son la Guía para un uso no sexista del lenguaje, que incluye una mirada especial al empleo y la discapacidad, publicada en 2018 por la Fundación Once en España, o el Manual para el uso no sexista del lenguaje publicado en 2011 por la Comisión Nacional para Prevenir y Erradicar la Violencia contra las Mujeres de México.

Algunos cambios pasan por la utilización de genéricos reales, masculinos o femeninos, que nombran de manera colectiva a hombres y mujeres: persona, alumnado, infancia, etcétera. Si no se encuentra este genérico hay que usar las dobles formas, los dos géneros o nombres abstractos o formas personales de los verbos y uso de pronombres. Hay que flexibilizar el uso de las palabras (niñas y niños, educadora y educador, etcétera) y, muy importante, dotar el discurso de homogeneidad: cuando se adopta una medida no sexista hay que mantenerla y tener presente que la función principal del lenguaje es la comunicación, y cuanto más reflejada quede la realidad que queremos decir y explicar, mejor será la comunicación.

La lengua siempre tiene una solución u otra para visibilizar, representar y denominar a las niñas, a las mujeres y otras colectividades.

\section{El ámbito relacional y la ocupación de los espacios}

Las personas nos hemos socializado desde nuestro nacimiento en diferentes ámbitos, y los más importantes han sido el ámbito familiar y la escuela, donde hemos aprendido de manera consciente (memoria explícita) y también inconsciente (memoria implícita) la forma de relacionarnos entre nosotros y nosotras, y hemos adquirido las características de género de nuestra cultura. El género, como construcción social, tiene que ver con el modo en que percibimos el mundo, con nuestra identidad y con nuestras respuestas frente a los estímulos que percibimos externamente y que nos conducen a adquirir una identidad social. Hemos interiorizado unas normas sociales marcadas por el género que han encaminado nuestra manera de vivir, que desde nuestras primeras 
manifestaciones personales nos han llevado a comportarnos de manera diferente niños y niñas (Subirats y Tomé, 2007).

Esta primera impronta de la socialización recibe un esfuerzo constante de la sociedad, que hará que se mantengan diferencias de comportamiento, intereses y percepciones entre mujeres y hombres, confirmando un aparente y no real carácter biológico de estas diferencias, reafirmadas por la sociedad patriarcal en la que vivimos.

En definitiva, los estudios de género y la deconstrucción de roles y estereotipos sexistas nos permiten descubrir que en la construcción social de los géneros nos referimos a patrones de comportamiento y formas de actuar que las sociedades atribuyen a los hombres o a las mujeres, y los educadores y educadoras tienen ahora la oportunidad de identificarlo y transformar la manera como se relacionan con niñas y niños en el ámbito de la educación formal y, en este caso, de la educación no formal, en el entorno patrimonial.

Los estudios sociológicos a los que hace referencia este artículo son ejemplo de que se pueden variar conductas y patrones de relación entre personas docentes y alumnado. En la medida en que los géneros son patrones sociales construidos, limitan las posibilidades de las personas que, sin ser conscientes, actúan desde la infancia, facilitando o inhibiendo el desarrollo de las capacidades, las posibilidades y los deseos de cada individuo de una manera inconsciente. Cuando se detectan estas limitaciones se puede decidir cambiarlas.

Subirats y Tomé (2007) definen los géneros como descriptivos o prescriptivos. Los descriptivos describen comportamientos y actitudes que adoptan mujeres y hombres libremente, sin que nadie trate de imponerlos. Los prescriptivos son los modelos sociales existentes a priori que la sociedad impone a niños y niñas, y les exige que se comporten, de manera implícita, de acuerdo con estos patrones. Las evidencias sociológicas demuestran que los modelos de género son prescriptivos, aunque hayan variado algunas de las prescripciones que comportan en cada caso, y sobre todo la rigidez de estos modelos y la dureza de las sanciones que conllevan las transgresiones, sobre todo de manera individual. Se pueden poner muchos ejemplos, como el de las personas que no siguen los patrones de género binario, que están expuestas a críticas, burlas o sanciones más severas, solo por romper las normas de género prescritas socialmente.

El sistema educativo, formal y no formal, también transmite estas pautas prescriptivas mediante la interacción entre personas educadoras y alumnado: normas y maneras de comportarse y relacionarse muy importantes en la adquisición de actitudes posteriores que configuran aprendizajes paralelos. En Rosa y azul (Subirats y Brullet, 1988) y en Balones fuera (Subirats y Tomé, 2007) se analiza cómo se dirigen las personas educadoras a los y las alumnas, cuáles son las imágenes que tienen de ellos y de ellas y cómo valoran sus actitudes. Los resultados son sorprendentes y las autoras explican que no 
son diferentes de los de otros estudios de las mismas características hechos en Estados Unidos o en Inglaterra.

Se confirma reiteradamente que los y las docentes, con independencia de que sean hombres o mujeres, dedican más atención al comportamiento de los niños, les hacen más preguntas, les dan más indicaciones para trabajar, les hacen más críticas y les riñen más. Las causas de este trato diferenciado pueden ser que los niños son más variables en sus conductas que las niñas, y los y las docentes tienen que estar más pendientes de ellos y controlarlos más. Otra hipótesis es que las niñas se distraen más, pero es una hipótesis que cae cuando se comprueba que los y las docentes no están atentos al alumnado más retrasado, sino que la mayor interacción la tienen con los niños más avanzados del grupo clase, por cuestiones relativas al trabajo escolar.

Con las niñas se interactúa menos. Ellas adoptan una actitud más pasiva a medida que se habla menos con ellas y aumenta notablemente su participación cuando se las estimula en la misma medida que a los niños. Su aportación en el momento de hablar tiene que ver con lo que se está haciendo en la clase y no con sus vivencias personales fuera del ámbito escolar, que son las que expresan sobre todo los niños. Las niñas, por su socialización, interiorizan un papel secundario y poco importante, adoptan una actitud más pasiva en relación con los niños, a los que se les otorga un papel más activo, dejando que ocupen los espacios en los debates y asambleas que se dan en el ámbito escolar. Este protagonismo se ve reflejado también en el patio o la clase, donde ocupan los espacios centrales e imponen sus juegos, como evidencian Subirats y Tomé (2007) o Cantó Alcaraz y Ruiz Pérez (2005).

El análisis sociológico de esta interacción muestra la existencia de prejuicios y pautas de comportamiento no explícitas que las y los docentes usan en su interrelación con niñas y niños, las cuales contradicen en parte los valores del sistema educativo, como, por ejemplo, la aceptación de las normas y la disciplina. La docilidad es un valor negativo en la sociedad actual, un signo de pasividad, igual que no saber imponerse. Este hecho hace que el mal comportamiento de los niños sea considerado una prueba de personalidad activa y fuerte, que es valorada aunque no se lo diga abiertamente. Esta valoración es percibida por los niños, y como consecuencia aumentan las conductas conflictivas en ellos (Subirats y Tomé, 2007; Subirats, 2017). En los estudios de Marina Subirats (Subirats y Brullet, 1988; Subirats y Tomé, 2007; Subirats, 2017) también se hace patente que, si las niñas rompen esta norma, reciben sanciones más duras por ser un comportamiento menos tolerado en ellas; se rompe una norma de género de las que denominamos prescriptivas. Las niñas se tienen que llevar bien y esta actitud más pasiva se considera como falta de personalidad y de docilidad.

El orden de género prescriptivo es jerárquico, y todo lo que hacen los niños es más valorado que lo que hacen las niñas, aunque muchas veces los comportamientos de las niñas se acerquen más a las normas explícitas del sistema educativo. 
Se llega a la conclusión de que el sistema educativo es sexista, que el niño es el protagonista de la acción educativa y las niñas se sitúan en un segundo término, más pasivo. El modelo pedagógico es androcéntrico y ha sido construido teniendo en cuenta la actividad pública y productiva atribuida tradicionalmente a los hombres, aunque las niñas también puedan acceder a ella. Esta idea entronca con la división sexual del trabajo, que para Trinidad Escoriza y Raquel Piqué (2011), prehistoriadoras especialistas en arqueología feminista, es un modelo organizativo que ha desempeñado un papel muy importante en los modelos de evolución humana que se han mantenido en la explicación de los atributos de las sociedades modernas, como algo naturalizado e inherente a nuestra especie, justificando los estereotipos de género y la discriminación del género femenino.

Para que la enseñanza sea realmente coeducativa, es necesario formular un nuevo modelo de coeducación que integre a las niñas en las profesiones tradicionalmente masculinas, reforzando su seguridad en sí mismas, cambiando las relaciones entre personas docentes y alumnado, e introduciendo en el currículo escolar y en las relaciones en el aula un conjunto de saberes que han estado ausentes (la cura o los cuidados de los y las otras y las necesidades afectivo-relacionales), así como la valoración de las actitudes y capacidades a las que no se les había prestado atención y tienen que ser convertidas en conductas positivas tanto en las niñas como en los niños. Los valores atribuidos tradicionalmente a las niñas y a los niños se tendrían que considerar y transmitir con la misma importancia por las personas docentes, puesto que forman parte de la sociedad y son necesarios para la vida colectiva.

Para romper estas dinámicas es preciso que los y las educadoras presten atención durante el desarrollo educativo de quien participa más y menos en el aula y favorezcan la participación equitativa, poniendo atención a las interrupciones de la palabra en los turnos de debate para cuidar el uso de las entradas participativas y controlar el habla dominante que se quiere imponer encima de otras opciones.

Si pensamos en cómo agrupar al alumnado, es importante favorecer grupos mixtos de trabajo y detectar, en caso de desequilibrio, las causas de la desproporción para buscar soluciones.

La observación de cómo se relacionan niños y niñas es importante para poder cambiar tendencias discriminatorias; por ejemplo, la manera como ocupan los espacios cuando el alumnado llega al museo - niños en el centro y en las zonas importantes cerca del material educativo; niñas en las periferias de las aulas taller, lejos de la persona educadora-, quién manipula el material educativo de los juegos y actividades que se proponen; quién recoge el material al finalizar la actividad educativa. Se trata de consideraciones importantes para cambiar los roles de género tradicionales y dar las mismas oportunidades de aprendizaje y la misma libertad a los niños, a las niñas y a otros niños 
o niñas con dificultades para relacionarse, bien por tener necesidades educativas especiales o por pertenecer a otras culturas migradas, hecho habitual en muchos centros educativos públicos.

Hay que poner atención en la erradicación de los mensajes que fomenten la violencia y el individualismo y aumentar el valor de las actitudes de cooperación y de cuidados, de empatía y respeto de las otras personas y no de rivalidad y competición, y trabajar por una cultura de paz. La coeducación es una oportunidad para llevar a cabo un cambio cultural y dar libertad a los niños, niñas y personas jóvenes, dejando que su naturaleza se desarrolle de una manera espontánea, sin tratar de imponerles unos comportamientos y unos modelos de género que son obsoletos, discriminatorios y con consecuencias nefastas para las relaciones sociales actuales (Subirats, 2017).

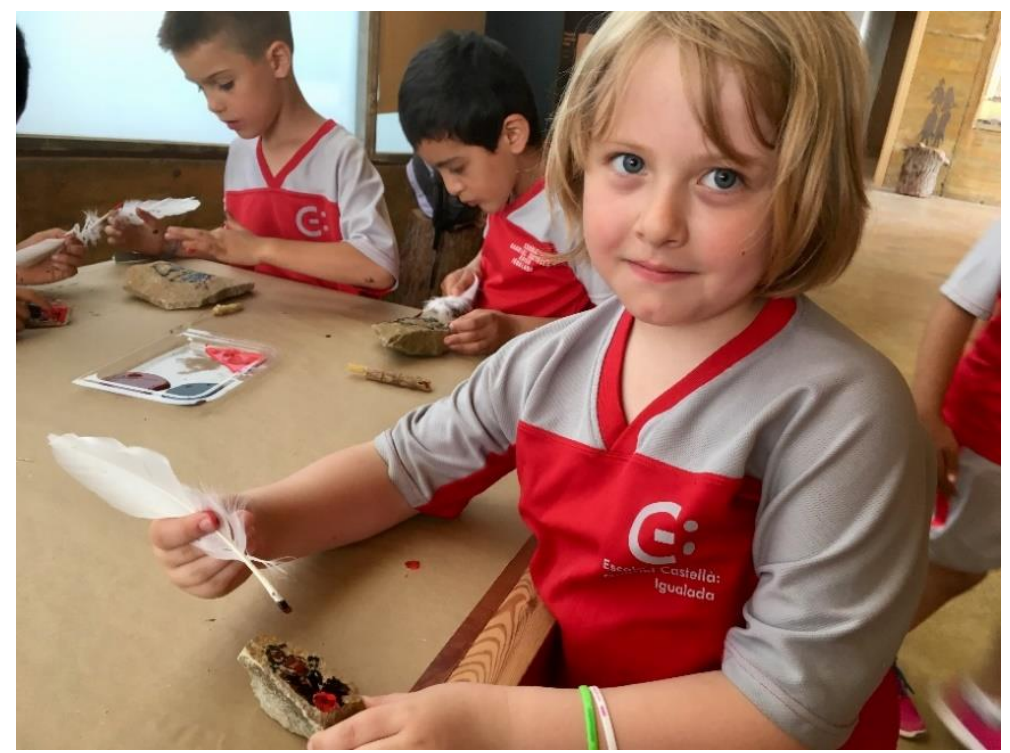

Figura 6. Seguimiento de la actividad educativa. Fotografía: Cacheda (2018). 


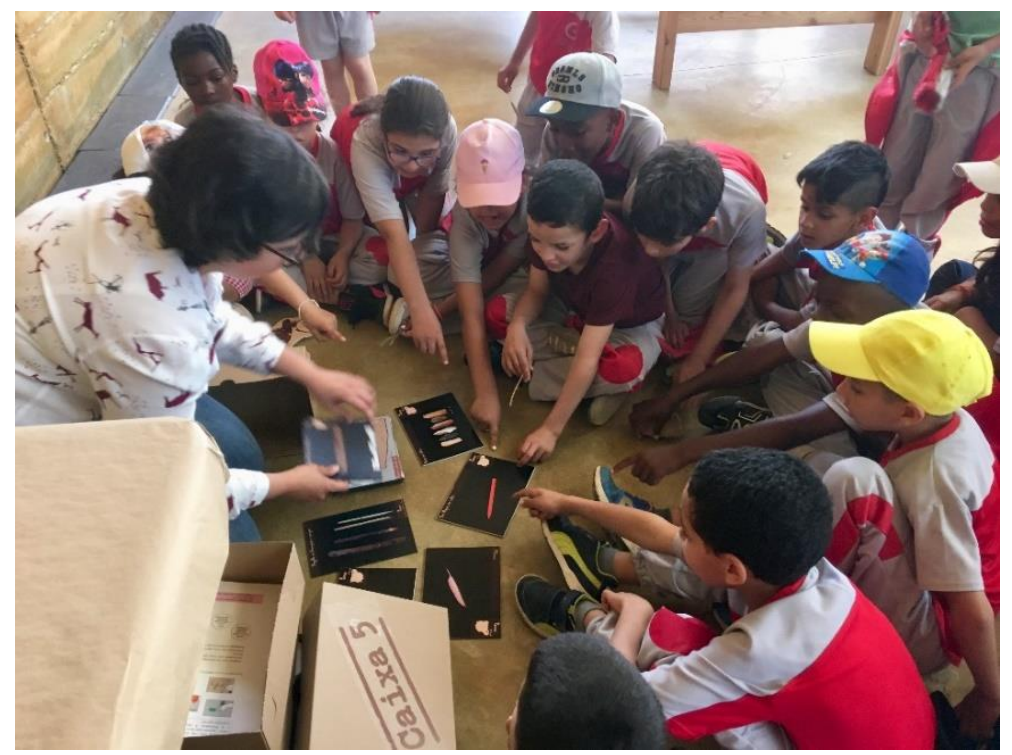

Figura 7. Seguimiento de la actividad educativa. Fotografía: Cacheda (2018).

«Se trata de crecer desde el respeto verdadero a los y las otras, aceptando la diferencia, y dejar de imponer comportamientos artificiales que niegan la propia naturaleza del ser humano», como dice Eduard Vallory en la introducción del libro Coeducación, apuesta por la libertad, de Marina Subirats (2017, p. 17).

\section{Metodología de análisis y evaluación del ámbito relacional}

Dentro del Área de Monumentos y Yacimientos, a través de un programa de evaluación propio, se analiza el ámbito relacional, haciendo un seguimiento específico del desarrollo de las actividades educativas. Este programa de evaluación, que se ha aplicado en el Conjunto Rupestre la Roca de los Moros del Cogul, ha sido creado con perspectiva de género y está integrado por un protocolo de observación de la actividad educativa por una persona evaluadora externa experta en coeducación, un cuestionario de valoración para las personas docentes, otro para el alumnado y otro para las personas educadoras patrimoniales. La finalidad es plasmar las impresiones y observaciones de todos los agentes que intervienen en una actividad educativa patrimonial (Cacheda Pérez y Granell Querol, 2019). 
Este programa de evaluación implica y escucha la opinión de todas las personas intermediarias que participan en la actividad educativa patrimonial: evaluadora externa, profesorado, alumnado y educadoras patrimoniales. Se trata de analizar de qué manera han percibido y valorado la actividad educativa las personas implicadas en la actividad, con el fin de orientar los resultados hacia una mejora, en este caso, que tenga en cuenta la inclusión de la coeducación patrimonial.

Las observaciones in situ del seguimiento de la actividad educativa, sumadas al registro escrito de la experiencia y los procesos por los cuales han pasado las personas educadoras patrimoniales y el alumnado durante el transcurso de la acción educativa, nos ofrecen las claves para evaluar las relaciones que se establecen entre personas educadoras, niñas y niños, y entre ellos y ellas, y con el entorno, y hacer una lectura coeducativa. Con los resultados, se puede extraer un conjunto de primeras medidas a tener en cuenta para establecer un nuevo modelo en coeducación patrimonial, aplicarlo y extrapolarlo a otras experiencias que se quiera construir en coeducación patrimonial.

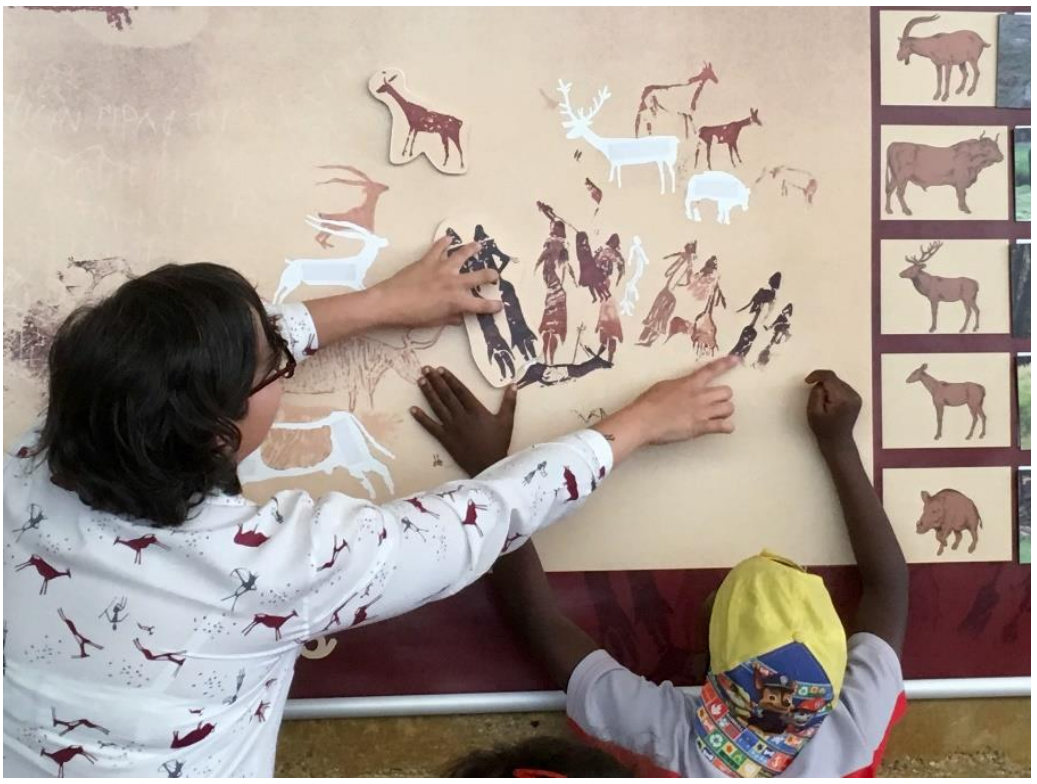

Figura 8. Seguimiento de la actividad educativa. Fotografía: Cacheda (2018).

A continuación, se exponen las pautas de observación trabajadas en los seguimientos de las actividades educativas patrimoniales en el Centro de Interpretación de la Roca de los Moros del Cogul, y las intervenciones y los cambios que se proponen a la hora de enfrentarse la persona educadora patrimonial a la ocupación del espacio por el alumnado, la relación entre niños y niñas, y la relación directa entre la persona educadora y 
el alumnado. Estas pautas nos servirán para aplicarlas en los programas de actividades educativas de cualquier museo o institución patrimonial y garantizar que las instituciones públicas tengan un compromiso de trabajar por la igualdad de género, tal y como reclama la sociedad actual.

\section{Ocupación del espacio}

Pautas de observación a tener en cuenta durante el seguimiento de la actividad:

- Número y proporción de niños y niñas que ocupan el centro del espacio, cerca de la persona educadora.

- Número y proporción de niños y niñas que se sitúan en zonas periféricas: detrás, a los costados, etcétera.

- Número de niñas que manipulan material. Número de niños que manipulan material.

- Número de niñas en plan de apoyo. Número de niños en plan de apoyo.

- Número de niños que recogen material. Número de niñas que recogen material.

Intervención y cambios, a posteriori:

- Que todo el alumnado tenga oportunidad de ocupar en algún momento los espacios considerados más valiosos: cerca de la persona educadora, cerca del material educativo, etcétera.

- Que las acciones y los juegos de todo tipo sean equitativos y compartidos entre niñas y niños.

- Eliminar jerarquías de género preestablecidas favoreciendo grupos mixtos e interculturales.

\section{Relación entre niñas y niños}

Pautas de observación a tener en cuenta durante el seguimiento de la actividad:

- Número de niñas que interactúan.

- Número de niños que interactúan.

- Número de niños y niñas que interactúan entre sí.

- Número y proporción de niños y niñas que se ofrecen como voluntarias.

- Número y proporción de niñas y niños en actitudes aparentemente pasivas.

- Número y proporción de niñas y niños implicados en situaciones de conflicto.

- Número y proporción de niñas y niños que desconectan. 
- ¿La interacción entre el alumnado es positiva? ¿Qué tipo de interacción realizan?

Intervención y cambios, a posteriori:

- En el trabajo cooperativo, favorecer grupos mixtos e interculturales, conscientemente.

- Romper las jerarquías de género preestablecidas, siempre que se den.

\section{Relación persona educadora-alumnado}

Pautas de observación a tener en cuenta durante el seguimiento de la actividad:

- ¿El alumnado participa en las tareas propuestas por la persona educadora?

- ¿El alumnado presta atención a las explicaciones de la persona educadora?

- Número de niños con los que interactúa directamente durante la mediación.

- Número de niñas que la persona educadora elige como voluntarias.

- Número de niños que la persona educadora elige como voluntarios.

- Número de niñas y de niños con las que la persona educadora interactúa directamente durante la mediación.

- ¿La persona educadora está más pendiente de las chicas o de los chicos?

- ¿A qué género presta más atención la persona educadora?

- ¿La persona educadora integra minorías étnicas?

- ¿La persona educadora conoce el nombre de pila del alumnado?

Intervención y cambios, a posteriori:

- Favorecer la participación equitativa consciente a la hora de elegir personas voluntarias.

- Gestionar equitativamente los grupos de trabajo.

- Dirigirse a niños y niñas por su nombre.

- Usar un lenguaje inclusivo.

- Gestionar equitativamente la ocupación de los espacios.

- Deconstruir discursos y actitudes androcéntricas, fomentando los principios de la comunicación no violenta.

Aplicando estos cambios, la coeducación patrimonial se convierte de esta manera en una herramienta de transformación social que promueve una educación patrimonial crítica para deconstruir los discursos androcéntricos del pasado, que revierte en discursos igualitarios e inclusivos en nuestro presente y en nuestra manera de relacionarnos. 


\section{Conclusiones}

La metodología creada por la autora se puso en práctica durante el año 2018 con el seguimiento de las actividades educativas en el centro de interpretación de la Roca de los Moros del Cogul. Se analizaron los tres ámbitos de la coeducación patrimonial propuestos: el relato sobre la prehistoria, el lenguaje utilizado hablado y escrito, y el ámbito relacional.

Las primeras conclusiones a las que se llega es que las educadoras del centro conocen muy bien los temas de las actividades y el relato sobre las sociedades prehistóricas, aunque en la incorporación del discurso necesitan mejorar la inclusión en una sociedad más participativa, donde los roles de género sean compartidos. Todavía se percibe la idea arraigada de que los hombres cazaban y las mujeres recolectaban y se dedicaban a trabajos más pasivos y poco especializados.

El tema del lenguaje es uno de los más difíciles de variar, sobre todo en el discurso y en la manera de dirigirse las educadoras a los niños y a las niñas. El uso del masculino genérico es habitual y tratar de niños a todo el colectivo. Esta tendencia ha mejorado con el uso de pegatinas con el nombre de cada niño o niña, lo que permite a la educadora dirigirse por el nombre.

Las intervenciones y los cambios que se proponen en el apartado anterior sobre el ámbito relacional de la coeducación patrimonial tienen que ver con las conclusiones de los seguimientos.

Durante los seguimientos hemos comprobado que, a medida que niños y niñas se van haciendo mayores, las relaciones que van estableciendo entre ellas y ellos son más diferenciadas. Se comprueba que los niños tienen tendencia a juntarse entre ellos, a desconectar más rápido de la actividad y a buscar el protagonismo, aunque sea para responder preguntas o hablar sobre temas que no se están tratando en ese momento. En cambio, las niñas, empiezan a no destacar, a hablar solo cuando la educadora se lo pide y a participar cuando se les presta atención.

En cuanto a la manipulación del material educativo que se usa durante la actividad, niñas y niños más pequeños y pequeñas lo hacen de manera más igualitaria, todos y todas se acercan a tocarlo y observarlo. Las niñas y niños de más edad se diferencian, puesto que hemos visto que los niños tienen tendencia a agarrarlo y no compartirlo, y las niñas no lo piden, se quedan esperando a que los niños dejen de utilizarlo.

Lo mismo pasa cuando se les pide como voluntarios o voluntarias que realicen alguna tarea o simplemente contesten preguntas. El alumnado más pequeño pide participar de manera más libre, y en el alumnado más grande destaca la voluntariedad masculina, aunque después no sepan muy bien de lo que se está hablando o qué se tiene que hacer. También son los primeros que pierden la concentración y abandonan el trabajo que estaban haciendo. 
Con respecto al espacio y cómo lo ocupan, se detecta que los niños son los que quieren situarse cerca del material y cerca de la educadora, impidiendo que las niñas se puedan situar en un primer término, o más cerca de donde se genera la acción.

El trabajo compartido se hace de manera más positiva y colaborativa con los niños y niñas más pequeños y pequeñas, en cuyos grupos espontáneos la equidad es más diversa. En cambio, en el alumnado mayor, los grupos que se forman tienen tendencia a separarse por géneros y hacer un trabajo más en grupos pequeños del mismo género. Se consigue que el trabajo individual sea productivo y positivo; destaca la tendencia de los niños a acabar antes las tareas, pero de manera menos reflexionada y cuidada.

Después de los seguimientos de las actividades podemos extraer algunas conclusiones generales para la mejora equitativa de la relación que se establece entre las educadoras y el alumnado. La primera conclusión es que hace falta mucha formación sobre coeducación para identificar las herencias androcéntricas explícitas en las maneras de relacionarnos, a fin de modificarlas y transformarlas.

Las alternativas de acción pasan por cambiar el relato, interiorizar un discurso inclusivo, tener presentes a niñas y niñas en nuestras acciones y en la manera como nos dirigimos a ellas y ellos. También vigilar el uso equitativo de los materiales y el espacio más prestigioso, donde se desarrollan las acciones, para que pueda ser ocupado por niños y niñas de manera igualitaria, sin discriminación, rompiendo estereotipos y jerarquías de género, individualismos y violencias.

El modelo educativo a aplicar tiene que ser transversal y basado en el trabajo competencial cooperativo, por el que los grupos logran los objetivos de aprendizaje cuando todos y todas los consiguen, lo que propicia el hecho de trabajar con otras personas y no contra ellas, dejando de lado el trabajo competitivo y trabajando por una cultura de paz que favorezca el respeto y la autoestima individual y grupal del alumnado.

\section{Referencias bibliográficas}

Acaso, M. y Manzanera, P. (2015). Esto no es una clase: Investigando la educación disruptiva en los contextos educativos formales. Madrid: Fundación Telefónica.

Arranz, F. (2015). Aproximación al dispositivo de reproducción de las identidades de género en la literatura infantil y juvenil de ficción. En A. Hernando (ed.), Mujeres, hombres, poder: Subjetividades en conflicto (pp.55-82). Madrid: Traficantes de Sueños.

Araya Umaña, S. (2003). Relaciones sexistas en la educación. Revista Educación, 27(1), 41-52.

Breuil, H. (1908). Les pintures quaternaries de la Roca del Cogul. Butlletí del Centre Excursionista de Lleida, 1, 10-13. 
Cabré Aguiló, J. (1915). El arte rupestre en España. Comisión de Investigaciones Paleontológicas y Prehistóricas, 1.

Cacheda Pérez, M. y Granell Querol, A. (2019). Programas educativos patrimoniales: ¿Producto comercial o aprendizaje significativo? La importancia de la evaluación. Propuesta metodológica cualitativa de evaluación de actividades educativas. Memoria Viva, 11, 109-122.

Cacheda, M. (2018). Educació patrimonial i coeducació: Fer visible allò que no es veu. Estratègies per a la coeducació patrimonial al Conjunt Rupestre de la Roca dels Moros del Cogul (Les Garrigues, Lleida). En Planificación y gestión: Acceso a los contenidos. 5è Congrés Internacional Educació i Accessibilitat a museus i patrimoni, Barcelona. Recuperado de: https://congresoaccesibilidad.mmb.cat/es/comunicaciones-nuevo/.

Cacheda Pérez, M., López Basanta, C. y Torres Fernández, A. (2017). El programa educatiu del conjunt d'art rupestre de la Roca del Moros (Cogul, Lleida): identitat, coeducació i competències per a la inclusió educativa. Her\&Mus, Heritage \& Museography, 18, 131-144.

Cantó Alcaraz, R. y Ruiz Pérez, L. M. (2005). Comportamiento motor espontáneo en el patio de recreo escolar: Análisis de las diferencias por género en la ocupación del espacio durante el recreo escolar. Revista Internacional de Ciencias del Deporte, 1(1), 28-45.

Comisión Nacional para Prevenir y Erradicar la Violencia contra las Mujeres (2011). Manual para el uso no sexista del lenguaje: Lo que bien se dice... bien se entiende. Recuperado de https://www.conapred.org.mx/userfiles/files/11.1_Manual_para _el_uso_no_sexista_del_lenguaje__2011.pdf.

Escoriza Mateu, T. (2005). Producción y trabajo femenino en las representaciones rupestres levantinas. En P. A. Cabal, R. Ontañón Peredo y C. García-Moncó Piñeiro (eds.), Actas del III Congreso del Neolítico en la Península Ibérica (pp. 729-738). Santander: Universidad de Cantabria.

Fundación ONCE (2018). Guía para un uso no sexista del lenguaje: incluye una mirada especial al empleo y a la discapacidad. Recuperado de https://www.cermi.es/sites/default/files/docs/novedades/GUIA.pdf.

García Prince, E. (2008). Políticas de igualdad, equidad y gender mainstreaming ¿De qué estamos hablando? Marco conceptual. San Salvador: PNUD.

Generalitat de Catalunya (2016). Agència Catalana del Patrimoni Cultural. Recuperado de https://cultura.gencat.cat/ca/departament/estructura_i_adreces/organismes/dgpc/accio/agencia_patrimoni/

González Marcén, P. (2000). Arqueología y enseñanza: La función social y educativa de los museos. Treballs d'Arqueologia, 8, 1-8. 
González Marcén, P. (2006). Dones i prehistòria: Viure el present, pensar al passat. En B. Soler, Les dones en la Prehistòria (pp. 15-26). Valencia: Museu de Prehistòria de València.

González Marcén, P. (2008). Tiempos de mujeres: Escala de análisis y metodología arqueológica. En L. Prados y C. López (coords.), Arqueología del género: 1 . $^{\text {er }}$ encuentro internacional en la UAM (pp. 61-76). Madrid: UAM.

González Marcén, P. (dir.) (2012). Los trabajos de las mujeres y el lenguaje de los objetos: Renovación de las reconstrucciones históricas y recuperación de la cultura material femenina como herramienta de transmisión de valores. Madrid: Instituto de la $\mathrm{Mu}$ jer.

González Marcén, P. y Picazo Gurina, M. (2005). Arqueología de la vida cotidiana. En M. Sánchez, Arqueología y género (pp. 141-158). Granada: Universidad de Granada.

Hernando, A. (2002). Arqueología de la identidad. Madrid: Akal.

Hernando, A. (2005). ¿Por qué la Historia no ha valorado las actividades de mantenimiento? Dones i activitats de manteniment en temps de canvi. Treballs d'Arqueologia, 11, 115-133.

Hernando, A. (2007). Sexo, género y poder: Breve reflexión sobre algunos conceptos manejados en la arqueología de género. Complutum, 18, 167-174.

Hernando, A. (2012). Teoría arqueológica y crisis social. Complutum, 23(2), 127-145.

Hernando, A. (2015). ¿Por qué la arqueología oculta la importancia de la comunidad? Trabajos de Prehistoria, 72, 22-40.

Lledó, E. (2005). De llengua, diferència i context. Barcelona: Institut Català de les Dones. (Quaderns de l'Institut, 3).

Piqué i Huerta, R y Escoriza Mateu, T. (2011). Una propuesta de estudio para el análisis de la división sexual del trabajo entre las comunidades del VI-IV milenios CAL ANE en el Nordeste peninsular: Las representaciones figurativas, los lugares de habitación y los espacios funerarios. Revista Atlántica-Mediterránea de Prehistoria y Arqueología Social, 13, 119-134.

Roset Fàbrega, M. (coord). (2008). Guia de coeducació per als centres educatius: Pautes de reflexió i recursos per a l'elaboració d'un projecte de centre. [Barcelona]: Institut Català de les Dones.

Sánchez Romero, M. (coord). (2005). Arqueología y género. Monografías de Arte y Arqueología. Granada: Universidad de Granada.

Sánchez Romero, M. (2007). Arqueología de las mujeres y las relaciones de género. Complutum, 18, 163-165.

Sánchez Romero, M. (coord.). (2008). Imágenes de mujeres de la Prehistoria: Desde las manifestaciones de la identidad femenina en el pasado a los estereotipos actuales [Dossier]. Arenal 15(1). 
Sánchez Romero, M. (2010). ¡Eso no se toca! Infancia y cultura material en arqueología. Complutum, 21(2), 9-13.

Sánchez Romero, M. y Alarcón García, E. (2015). Arqueología feminista, de las mujeres y del género en la Prehistoria de Andalucía. Menga. Revista de Prehistoria de Andalucía, 6, 33-59.

Subirats, M. y Tomé, A. (2007). Balones fuera: Reconstruir los espacios desde la coeducación. Barcelona: Octaedro.

Subirats, M. (2017). Coeducació, aposta per la llibertat. Barcelona: Octaedro. (El Diari de l'Educació, Recursos Educatius.)

Subirats, M. y Brullet, C. (1988). Rosa y azul: La transmisión de géneros en la escuela mixta. Madrid: Instituto de la Mujer.

Viñas, R., Rubio, A., Iannicelli, C. y Fernández Marchena, J. L. (2017). El mural de la Roca dels Moros, Cogul (Lleida): Propuesta secuencias del conjunto rupestre. Cuadernos de Arte Prehistórico, 3, 93-129. 